\title{
Algumas Considerações Sobre o Parecer Psicológico na Justiça da Infância e da Juventude
}

Some thoughts on psychological assessment in Infancy and Youth Justice

Resumo: Este artigo apresenta um estudo sobre o parecer psicológico na Justiça da Infância e da Juventude a partir dos conceitos de poder disciplinar, norma e exame tais como elaborados por Michel Foucault. A pesquisa constitui-se, também, de uma série de entrevistas com operadores do Direito e psicólogos que atuam nessa área, realizando-se uma análise dos pareceres produzidos. Elabora-se, assim, um painel onde aqueles conceitos propiciariam não apenas uma análise crítica do instrumento 'parecer psicológico', mas também das linhas de força para sua redefinição.

Palavras-Chave: Psicologia Jurídica, parecer psicológico, disciplina.

Abstract:This article is a study about the psychological written report in the Juvenile Court, based on the concepts of discipline, norm and exam as they were worked out by Michel Foucault. This research is also based on interviews with judges, prosecutors, defense attorneys and psychologists who work in this area. An analysis about some psychological written reports is also made. In the end, we cannot only criticize such reports, but work out the concepts of their (re)definition as well.

Key Words: Juridic Psychology, psychological report, discipline.

\section{José César Coimbra \\ Psicólogo na 1a Vara da Infância e da Juventude/RJ. Mestre em Teoria Psicanalítica/ UFRJ. Especialista em Psicologia Jurídica/UERJ.}

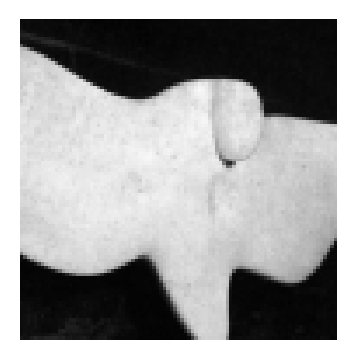

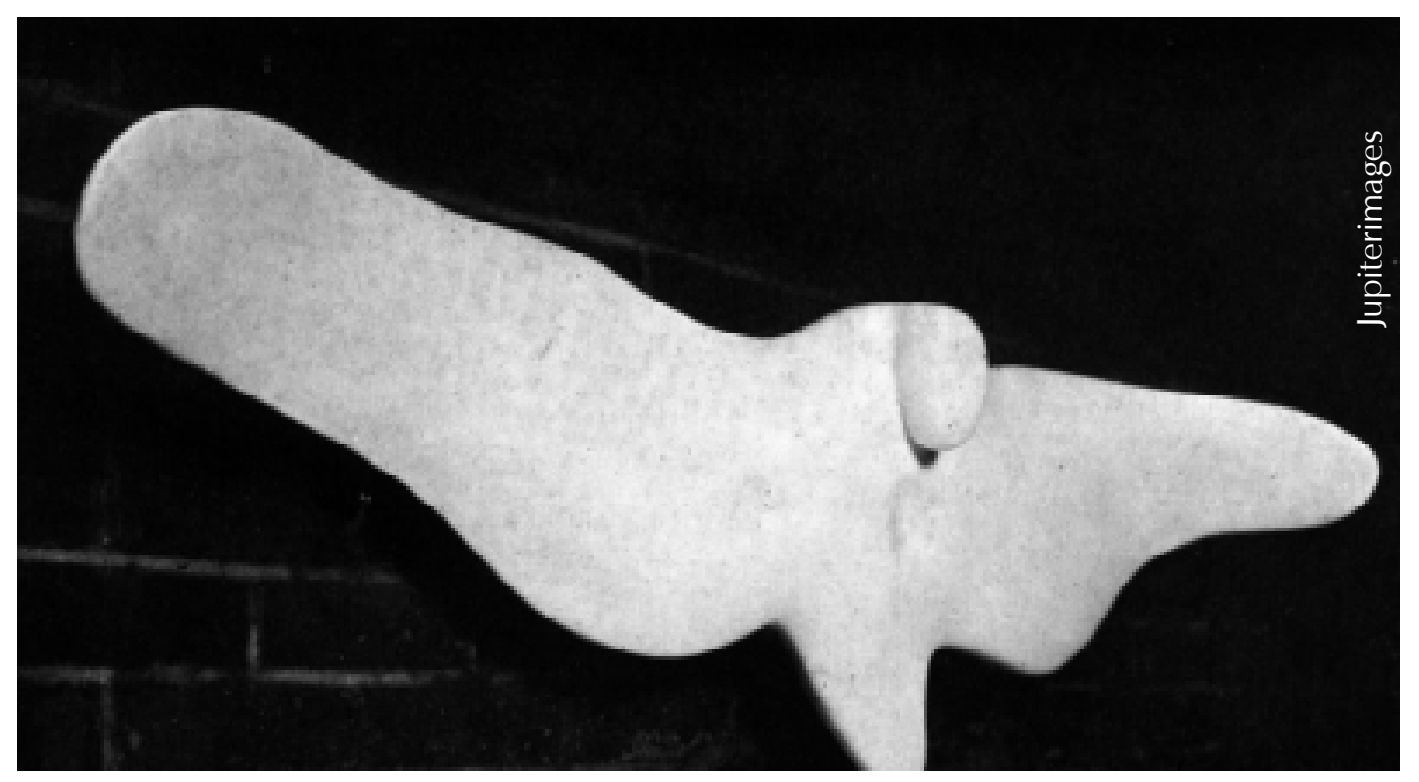

Este artigo tem por objetivo analisar a importância concedida a um instrumento legal: o parecer psicológico. Em particular, trata-se de interrogá-la num espaço muito peculiar do universo judicial: a área da infância e da juventude. Pode-se, de antemão, vislumbrar a importância do parecer. Trata-se, de certo modo, do ponto de convergência do trabalho do psicólogo, lugar onde suas elaborações irão adquirir materialidade própria, mensagem que será endereçada a um Outro, o qual se apoiará nelas em maior ou menor grau para uma tomada de decisão.
O estudo que serviu de base para este artigo foi composto de uma pesquisa de campo, onde foram entrevistados:

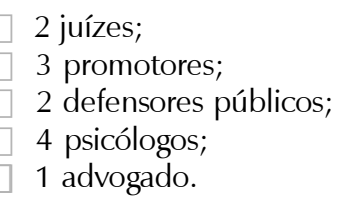

Foram analisados 46 pareceres, referentes ao período 1999 - 2000, elaborados por 5 psicólogos. 
Cumpre esclarecer que os pareceres analisados abordam os seguintes temas: adoção, habilitação para adoção - processo em que não existe ainda a criança ou adolescente que preenche o lugar de adotando, mas apenas a demanda dos requerentes de adotar - e representações cíveis e administrativas - as quais referem-se, fundamentalmente, aos diversos tipos de violência contra crianças e adolescentes.

O roteiro a partir do qual as entrevistas foram realizadas tem por base o quotidiano de elaboração de pareceres no universo judiciário. É comum, por exemplo, a interrogação sobre o que seria um parecer 'conclusivo', em que este se diferencia do parecer social e, fundamentalmente, que definição poderia ser dada a esse instrumento. É importante notar que tais questões são recorrentes não só no trato com os operadores jurídicos, mas também naquele com os demais membros da equipe multiprofissional, como os assistentes sociais.

As entrevistas e as análises dos pareceres foram apreciadas de uma perspectiva que se pautou largamente nas considerações de Foucault acerca da disciplina, da norma e do exame. Qual seria a relação entre esses conceitos?

\section{Disciplina: Exame e Norma}

O exame, tal como Foucault o delineia, é um modo de produção de verdade. Ao contrário do que ocorria no poder soberano, onde a visibilidade era a marca daquele a partir de quem as relações de força ganhariam sentido, o exame anuncia toda uma nova forma de manifestação do poder:

O poder disciplinar (...) se exerce tornando-se invisível; em compensação impõe aos que submete um princípio de visibilidade obrigatória (...) É o fato de ser visto sem cessar, de sempre poder ser visto, que mantém sujeito o indivíduo disciplinar. E o exame é a técnica pela qual o poder, em vez de emitir os sinais de seu poderio, em vez de impor sua marca a seus súditos, capta-os num mecanismo de objetivação (Foucault, 1988, p. 167).

O exame surge num momento em que há uma nova definição de criminoso, quer dizer, o criminoso passa a ser aquele que causa prejuízo, que perturba a sociedade, sendo, portanto, inimigo social. Nesse momento, entre o final do século XVIII e início do XIX, o que passa a existir...

...é a idéia do criminoso como inimigo interior, como indivíduo que, no interior da sociedade, rompeu o pacto que estava teoricamente estabelecido (...) (Foucault, 1994, p. 590).
O exame e a nova definição de criminoso guardam estrita correspondência com o que Foucault nomeou sociedade disciplinar. O exame é o instrumento através do qual o poder se manifesta e a verdade é produzida nesse regime. Aqui, não estaria mais em jogo a possibilidade de punir os indivíduos; trata-se, de modo diferente, de corrigir as suas virtualidades (Foucault, op.cit., p. 593), ou seja, intervir de modo que a própria infração não venha a ser cometida. Para tanto, a Justiça começa a servir-se de uma série de aparelhos, de instituições de vigilância e correção: a polícia, a Psicologia, a Psiquiatria, a Criminologia, a Medicina e a Pedagogia encontrariam aí as suas marcas de nascença (Foucault, 1994, p. 593).

O exame e o panóptico são manifestações daquele tipo peculiar de poder a que chamamos disciplina. Ambos têm como parâmetro a norma, produção de saberes a partir dos quais os indivíduos podem medir sua liberdade, ou, mais precisamente:

Um saber que tem agora por característica não mais determinar se alguma coisa aconteceu ou não, mas determinar se um indivíduo conduz-se ou não como é preciso, em conformidade ou não com a regra, se ele progride ou não. Esse novo saber não se origina mais em torno das questões: 'Isso foi feito? Quem o fez?' Ele não se organiza mais em termos de presença ou de ausência, de existência ou de não existência. Ele se ordena em torno da norma, em termos disso que é normal ou não, correto ou não, disso que se deve fazer ou não (Foucault, 1994, p.595, grifos nossos).

A essa discussão, Ewald (1993, pp.77-125) dedica particular atenção. Suas formulações são importantes porque retomam as considerações de Foucault a respeito do tema e explicitam a relação lei/norma. O autor afirma que a norma não se opõe à lei, mas ao tipo de poder associado à idéia de soberania, qual seja, o 'jurídico' (Ewald, 1993, p. 78). Sem dúvida, essa afirmação encontra apoio direto na tese desenvolvida em Vigiar e Punir. Ali, podemos ler que a norma funciona como um novo tipo de 'lei': "um misto de legalidade e natureza, de prescrição e constituição" (Foucault, 1988, p. 265), ou, para citar de modo mais extenso:

Daí toda uma série de efeitos: o deslocamento interno do poder judiciário ou ao menos de seu funcionamento; cada vez mais dificuldade de julgar, e uma tal qual vergonha de condenar; um desejo furioso de parte dos juízes de medir, avaliar, diagnosticar, reconhecer o normal e o anormal; e a honra reivindicada de curar ou readaptar (ibid.).

É nesse contexto que podemos notar de que modo o papel do psicólogo passa a ser possível no funcionamento da Justiça. No momento, podemos
A sentença não vem de uma vez, éo processo que se converte aos poucos emveredicto.

Kafka, O Processo 


\section{"O que é a norma, precisamente? A medida, que simultaneamente individualiza, permite individualizar \\ incessantemente e ao mesmo tempo torna comparável (...) Um princípio de comparação, de comparabilidade, uma medida \\ comum, que se institui \\ na pura referência de um grupo a si próprio, a partir do momento em que só se relaciona consigo mesmo, sem \\ exterioridade, sem \\ verticalidade [i.e. sem referência a uma natureza, a uma essência dos sujeitos.] (...) a individualização normativa é puramente comparativa (...)}

Ewald

1 Nessa proposta, também são apresentadas justificativas para a atuação do psicólogo nas varas de Família e Execução Penal. Todas as justificativas estão em consonância com as diretrizes previstas no Estatuto da Crianca $e$ do Adolescente, tais como referidos nos artigos 150; 161, $\S 10 ; 167$ e 186, § 40 ater-nos à 'Proposta de abertura de concurso público para o cargo de psicólogo', publicado no Diário Oficial do Estado do Rio de Janeiro, em 12.11.1997. Ali, é afirmado que "O serviço de psicologia é absolutamente necessário de ser implementado (...)" e que a maioria dos cargos a serem preenchidos estão nas Varas de Infância e da Juventude e Varas de Família. Afirma também que:

O exercício do cargo perante as Varas de Infância e Juventude proporcionará um acompanhamento efetivo dos diversos problemas que envolvem as crianças carentes e os adolescentes infratores, já que os psicólogos (...) comporão a equipe interdisciplinar, tão importante no assessoramento dos Juízes da Infância e da Juventude, que buscam em seus laudos os subsídios de ordem técnica para embasar os julgamentos que proferem diariamente ${ }^{1}$.

O 'deslocamento interno do poder judiciário' mencionado há pouco aparece, de certo modo, na citação acima. As questões relativas à norma assumem uma dimensão especial, sendo justamente o princípio que nos permite pensar a disciplina como não apenas associada ao enclausuramento. De modo diferente, trata-se de um conjunto de técnicas que visa a produzir indivíduos, tornando-os comparáveis:

O que é a norma, precisamente? A medida, que simultaneamente individualiza, permite individualizar incessantemente e ao mesmo tempo torna comparável (...) Um princípio de comparação, de comparabilidade, uma medida comum, que se institui na pura referência de um grupo a si próprio, a partir do momento em que só se relaciona consigo mesmo, sem exterioridade, sem verticalidade [i.e. sem referência a uma natureza, a uma essência dos sujeitos.] (...) a individualização normativa é puramente comparativa (...) [Ewald, 1993, p.86].

Ainda a respeito da norma, devemos entender que não há equivalência pura e simples entre esse conceito e aquele que denominamos disciplina (cf. Ewald,1993, p. 88), ou melhor, ambos não são sinônimos, embora mantenham relações específicas que nos fazem remeter um ao outro, tal como expusemos até aqui.

Se a disciplina visa ao corpo (Foucault, 1988, pp 153 e ss, 1990, p. 131 e 1994a), a norma é a medida, "uma maneira de produzir medida comum" (Ewald, 1993, p. 88). É importante notar que a referência explícita à relação disciplinacorpo de modo algum deve ser entendida como em contradição com a referência anterior disciplina-virtualidade. Foucault faz uma oposição entre virtualidade e ato, tendo como referência Beccaria, no sentido de que o poder deve assegurar o controle dos indivíduos através do controle dos seus comportamentos - "no momento em que estes se esboçam" (Foucault, 1994, p.593)- e não através de uma ação reativa, que poderia ser entendida como exclusivamente punitiva.

O que caracteriza a modernidade, para Foucault, é a normalização das disciplinas, é a passagem do que Ewald chama de disciplina-bloqueio à disciplina-mecanismo (Ewald, op.cit., pp.81-2). A primeira, ligada à função de um uso delimitado do espaço, de neutralização dos perigos, onde as populações deveriam ser fixadas e dispersadas, de certo modo, um valor negativo ainda; a segunda, referindo-se propriamente à função de otimização do indivíduo, maximização de sua utilidade (Foucault, 1988, pp. 130 e ss.). É esse segundo aspecto da disciplina que está na base do que Foucault denomina sociedade disciplinar.

Devemos lembrar que Foucault relaciona três grandes instrumentos disciplinares: a vigilância hierárquica, a sanção normalizadora e o exame (Foucault, 1988, p. 153 e ss e Ewald, 1993, p. 83). Quanto ao último, ressalta:

O exame combina as técnicas da hierarquia que vigia e as da sanção que normaliza. É um controle normalizante, uma vigilância que permite qualificar, classificar e punir. Estabelece sobre os indivíduos uma visibilidade através da qual eles são diferenciados e sancionados. É por isso que, em todos os dispositivos de disciplina, o exame é altamente ritualizado. Nele vêm-se reunir a cerimônia do poder e a forma da experiência, a demonstração da força e o estabelecimento da verdade (Foucault, 1988, pp. 164-5).

É com um outro nome que reencontraremos logo o exame. Esse instrumento, em que produção de visibilidade e produção de saber tornam-se quase sinônimos, é o ponto em torno do qual este trabalho gira, é a razão da pergunta que nos orienta. Poderia o parecer psicológico ser algo diferente?

\section{As Entrevistas - $1^{\mathrm{a}}$ parte: Os Operadores do Direito}

A apresentação precedente encontrará, a seguir, uma primeira forma de atualização através das entrevistas realizadas com os operadores do Direito. A nossa "chave de leitura", que permitirá a passagem para esta seção, será a seguinte citação:

O exame combina as técnicas da hierarquia que vigia e as da sanção que normaliza. É um controle normalizante, uma vigilância que permite qualificar, 
classificar e punir. Estabelece sobre os indivíduos uma visibilidade através da qual eles são diferenciados e sancionados [...] (Foucault, 1988, pp. 164-5, grifos nossos).

Iremos deter-nos, agora, nas entrevistas realizadas:

O Que é o Parecer Psicológico? Não houve uma variação significativa no rol de respostas oferecidas: 'análise das partes'; [indicação da] 'realidade psicológica das pessoas envolvidas'; [indicação do que é] 'o melhor para a criança'; [análise das] 'relações afetivas e emocionais das partes'; [ [análise das] 'condições emocionais'; 'avaliação do comportamento intrínseco' [daquilo que não pode ser visto]. Acrescente-se que, de um modo geral, todas essas respostas eram acompanhadas da especificação de que se trata de uma intervenção 'técnica', onde deve haver uma correlação entre causas, conseqüências e argumentos fundamentados, p.ex. Por vezes, houve tentativas de especificar o que seria 'psicológico'. O sinônimo recorrente era 'emocional', embora, repetidamente, houvesse, ao menos quanto a um entrevistado, o reconhecimento que essa palavra não recobriria integralmente aquela.

Qual sua finalidade? 'Orientar o juiz na decisão'; 'dirimir questões cujos aspectos psicológicos sejam relevantes'; 'subsídio endereçado ao juiz'; 'subsídios aos operadores do Direito para julgar questões não meramente jurídicas'; 'apontar o que é melhor para a criança'; 'notar o que os operadores não podem, devido ao pouco contato com as partes'; 'detectar se a criança está sendo bem assistida, se o pedido trará benefícios a ela'. Aqui, é interessante notar que a tendência é ligar o parecer ao juiz, no sentido de que ele seria o destinatário do trabalho realizado. Formalmente, é possível entender a resposta majoritária, pois os psicólogos estão administrativamente subordinados ao juiz. No entanto, é interessante perceber que, de fato, o processo é um campo de correlação de forças entre as diversas entidades que o compõem: juiz, promotor, defensor, advogado e partes. Nesse sentido, o parecer é apropriado por essas entidades de modo diferente e sofre ressignificações diversas, conforme as estratégias, interesses, valores e entendimento da situação a ele correspondente. Todavia, a idéia de uma hierarquia, de uma ordem na transmissão do saber construído, é pertinente às características do exame.

Qual a principal expectativa quanto ao parecer? 'Que mostre o melhor caminho no interesse superior da criança'; ' Confirmar ou não se as partes envolvidas têm estrutura psicológica adequada'; 'que atenda ao interesse da parte [ou da criança/ adolescente]'; que seja 'conclusivo'; 'que tenha fundamento, que descreva a história da pessoa'. Essas respostas revelam, de modo mais perceptível, a preocupação com algo da ordem da 'normalidade' e da vigilância, que já se anunciava nas respostas da pergunta anterior. Há que se notar que a ênfase dos enunciados não é a de que o parecer é um instrumento para revelar o que 'realmente aconteceu'. Feita a ressalva de que estávamos falando do parecer 'em geral', como dito por um entrevistado, podemos entender que, mesmo nos casos de violência sexual, seja algo do mesmo sentido que está sendo esperado, isto é, espera-se uma última palavra que possa dizer o que aconteceu, mas tal palavra vai ser construída pari passu com a descrição e a análise dos 'aspectos psicológicos' daquele que é alvo do estudo. Em outras palavras, estará em perspectiva o grau de normalidade do sujeito, no sentido de que a norma permite individualizar e comparar.

Em que o parecer psicológico se diferencia do social? Os entrevistados definiram o parecer psicológico como dizendo respeito a aspectos subjetivos, afetivos, implícitos, emocionais, internos, comportamentais. O parecer social faria referência aos dados objetivos, condições físicas, habitabilidade e condições externas. Há que se ressaltar que vários operadores reconheceram que, de fato, não acreditam que tais aspectos sejam inteiramente dissociados, de tal modo que, nos relatórios psicológicos e sociais, percebem, às vezes, certa mescla. Todavia, foram unânimes em afirmar que sabem onde encontrar as informações de que precisam, conforme se trate de uma questão relativa ao aspecto psicológico ou social. Ao conjugar um e outro parecer, podemos notar que há um enquadramento daquele que está sendo avaliado. Nesse sentido, é interessante notar, principalmente nos casos relativos à habilitação para adoção, a recorrência à palavra 'idôneo'. 'O requerente é idôneo para a adoção ou não?'. Para além da carga moral associada à palavra, seu significado prestase ao entendimento que algo "é próprio para alguma coisa; conveniente, adequado; que tem condições para desempenhar certos cargos ou realizar certas obras" (v. Aurélio). Trata-se, mais uma vez, das idéias de norma e disciplina associadas à intervenção da equipe técnica.

O que é um parecer conclusivo? 'É aquele que sugere a procedência ou improcedência do pedido'; 'aquele que dirime as questões, que sugere medidas, independentemente da previsão legal'; 'é o que afirma com quem a criança deve ficar, se uma determinada situação ocorreu ou não'; 'define a situação, fala das condições'. É interessante acrescentar que, nessa pergunta, um dos

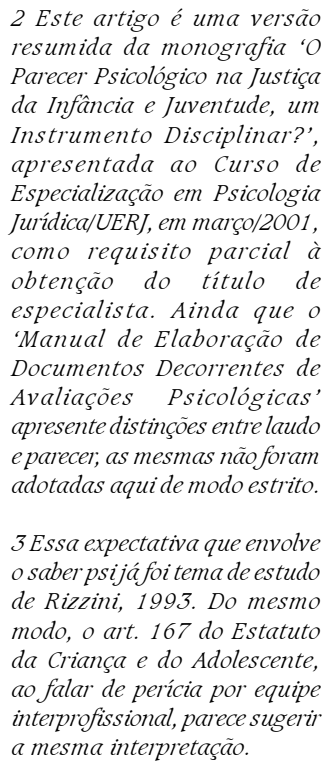
resumida da monografia ' $O$ Parecer Psicológico na Justiça da Infância e Juventude, um Instrumento Disciplinar?', apresentada ao Curso de Especialização em Psicologia Jurídica/UERJ, em março/2001, como requisito parcial à obtenção do título de especialista. Ainda que o 'Manual de Elaboração de Documentos Decorrentes de Avaliações Psicológicas' apresente distinçóes entre laudo e parecer; as mesmas não foram adotadas aqui de modo estrito.

3 Essa expectativa que envolve o saber psijá foi tema de estudo de Rizzini, 1993. Do mesmo modo, o art. 167 do Estatuto da Criança e do Adolescente, ao falar de perícia por equipe interprofissional, parece sugerir a mesma interpretação. 
entrevistados afirma que a equipe técnica não deve mencionar aspectos legais (citar artigos, leis, p.ex.) em suas análises. Ele espera uma intervenção no ponto em que, sozinho, não seria capaz de apreender as nuanças em jogo. Nessa perspectiva, um outro operador comenta a ojeriza à expressão s.m.j. [salvo melhor juízo] pelo mesmo motivo. Se o parecer diz algo, deve dizê-lo sobre aquilo que o operador não pode, sozinho, deduzir. Ressalte-se que é esperado do parecer psicológico algo que seja decisivo, isto é, haveria algo da esfera psíquica, o que está, portanto, na alçada de investigação do psicólogo, que apontaria ao operador jurídico, ao juiz em particular, a decisão a ser tomada.

Quais seriam os principais itens que o parecer deveria responder? Por quê? $O$ parecer tem valor de prognóstico? 'Equilíbrio [emocional], razões do desejo, motivos da causa [provável] de uma violência, conseqüências de uma relação interpessoal, conseqüências da quebra de vínculo'; 'se há estrutura emocional adequada, motivação, perfil para serem bons pais emocionalmente'; 'se há vínculos'; 'o psicólogo com uma frase descobre tudo...'; 'se há adaptação'; 'entrevista com todos os envolvidos, [pois] trabalhamos para a verdade'; 'tudo que possa ser tirado da criança'. Todos afirmaram que o parecer tem valor de prognóstico, desde que mantidas as condições nas quais o estudo foi feito, ou seja, eles não acreditam que o parecer possa falar do futuro pura e simplesmente. Ao associarmos essa observação às respostas acima, temos, mais uma vez, os exemplos onde a verificação de adequabilidade ou, no limite, utilidade do indivíduo com relação a uma certa situação ou função, é o principal motivo de interesse do operador quanto ao parecer. Tais características poderiam ser entendidas sinteticamente sob o rótulo da 'disciplina'. Há que se destacar, novamente, a legitimação do instrumento como um equipamento de vigilância e de análise do que ainda não está revelado.

Quais os itens que não precisariam constar no parecer psicológico? As variações das respostas a essa pergunta também não foram grandes. De ordem pragmática, foi dito que 'não deve haver tecnicismo', 'citação de questões jurídicas', mas, fundamentalmente, foi dito que 'quanto mais [informação] melhor'. Nesse sentido, há estrita correspondência com as respostas anteriores, em particular com as mencionadas na pergunta 6 .

Sua formação e experiência profissional são exclusivas no Direito? Dos oito entrevistados, apenas dois tinham experiências profissionais diferentes daquela do Direito.

Há quanto tempo na VIJ? Um dos operadores tem 10 anos de trabalho junto à VIJ. No momento das entrevistas, o tempo médio dos demais era de um ano e meio. Aproximadamente $40 \%$ dos entrevistados situavam-se entre 1 e 8 meses de experiência na VIJ.

Há quanto tempo na magistratura/promotoria/ defensoria? Dois operadores têm 20 e 7 anos nas respectivas carreiras. Para os demais, há um tempo médio de 2 anos. Dois dos operadores estavam há 6 meses na atual carreira, sendo um deles oriundo de uma experiência de 10 meses na Defensoria Pública. O trabalho efetivo como advogado, antes do ingresso na carreira atual, não foi uma constante. Com exceção da advogada, apenas três entrevistados fizeram menção a essa experiência.

As três últimas perguntas tiveram o objetivo de verificar se haveria influência entre a experiência profissional e as respostas às questões anteriores. Todavia, salvo por uma ou outra observação relativa às rotinas da equipe técnica, não foram verificadas diferenças significativas nas respostas.

\section{As entrevistas - $2^{\mathrm{a}}$ parte:Os Psicólogos}

As mesmas perguntas acima relacionadas, com pequenas alterações, foram aplicadas a quatro psicólogos que trabalham na VIJ. Há que se destacar que, durante as entrevistas com os operadores do Direito, o trabalho dos psicólogos foi tido como fundamental e atendendo ao que se espera dele. Essa consideração é relevante, pois já fala por si, de certo modo, do lugar do psicólogo na máquina judiciária, bem como de sua eficiência.

O que é o parecer psicológico? 'Lugar onde os aspectos psicológicos, emocionais, pessoais, relevantes ao processo estão organizados para o juiz, de modo a auxiliá-lo numa tomada de decisão'; 'lugar no processo onde podem aparecer as partes enquanto sujeitos, num sentido psicanalítico, i.e., divididas, contraditórias etc.'; 'instrumento para os operadores do Direito. Visa a auxiliá-los numa tomada de decisão'; 'Coleta de dados especializada com um objetivo: [avaliar] a relação entre as partes ou entre estas e a criança/ adolescente'. A idéia de hierarquia encontra-se também presente aqui, mesmo que, às vezes, de modo implícito. Todavia, há maior variação quanto ao modo de definir o destinatário final do trabalho.

Qual sua finalidade? 'Responder ao juiz e sugerir novas perspectivas para o caso/processo'; 'refletir a intervenção'; 'respaldar uma decisão'; 'entender uma situação/relação, promover uma análise dos dados levantados'. A idéia de visibilidade, de produção de visibilidade e de sanção, ainda que não esgote o sentido das respostas dadas, de certo 
modo, traduz o conjunto de enunciados acima. Mais especificamente, pode-se deduzir que 'sugerir', 'respaldar', 'promover uma análise', ainda que não tenham necessariamente o mesmo sentido, guardam um traço em comum. Falam de uma certa especificidade do trabalho, cuja apresentação é demandada insistentemente pelos operadores do Direito, especificidade que estaria ligada àquilo que poderia 'escapar' aos recursos imediatos de que dispõem os referidos operadores para a apreensão do fato jurídico, bem como à sua solução.

Qual a principal expectativa quanto ao parecer? 'Que seja entendido e sirva para uma tomada de decisão, que seja um espaço de elaboração'; 'que cumpra o seu objetivo, atinja aquilo a que se propôs ao longo da intervenção'; 'alargar o campo de visão'; 'poder fornecer subsídios para a resolução positiva [do processo], ajudar na decisão judicial, que auxilie na superação dos litígios'. Aqui, é interessante destacar que um dos entrevistados fez a distinção entre expectativa do psicólogo com relação ao parecer e expectativa do psicólogo com relação à expectativa do operador jurídico quanto ao seu parecer. O sentido dessa distinção é ressaltar uma variável que perpassa o trabalho: uma certa ansiedade ante a sensação de que é preciso oferecer uma resposta ao que se vai fazer, ou, mais diretamente: 'Como se colocar diante da necessidade de sempre dar uma resposta?'. Outra observação que precisa ser feita é a preocupação sobre o entendimento ou o modo como o saber produzido será apropriado pelos operadores do Direito. Esse (des)entendimento atualiza-se de diversas maneiras: desde uma possível tomada de decisão, apoiada no parecer, mas não orientada conforme o esperado pelo psicólogo, até o retorno dos autos ao setor sob a determinação de elaboração de um parecer conclusivo.

Em que o parecer psicológico se diferencia do social? '[O parecer psicológico] é o resultado de um trabalho diferente. [Diz respeito] à subjetividade, conflitos, causas, [que muitas vezes escapam] do conflito jurídico [tal como ele se apresenta formalmente]'; 'o social refere-se ao consciente, o psicológico, às entrelinhas'; 'os limites não estão demarcados. O psicológico diz respeito à dinâmica familiar, às relações'; '[o parecer psicológico] refere-se às peculiaridades das relações'.

O que é um parecer conclusivo? 'É aquele que responde às questões que foram levantadas no trabalho pelo próprio psicólogo'; [o parecer] só é conclusivo a posteriori, dependendo dos efeitos'; 'é aquele que tem uma posição clara, seja aberta [com ênfase na análise e descrição] ou fechada [tipo $\operatorname{sim} /$ não]'; 'esclarece as peculiaridades das relações'. O conjunto das respostas às perguntas 3 e 5 insinua o que nas respostas dos operadores aparece como um imperativo: que as respostas oriundas do trabalho colaborem de modo decisivo para uma tomada de decisão. Nessas preocupações, deparamo-nos com aquilo que foi chamado por Foucault de 'deslocamento interno do poder judiciário': "cada vez mais dificuldade de julgar (...), um desejo (...) de parte dos juízes de medir, avaliar, diagnosticar, reconhecer o normal e o anormal (...) e a honra reivindicada de curar ou readaptar" (Foucault, 1988, p. 265). Quanto a essa referência, é interessante observar que o número de encaminhamentos para atendimento psicológico sugerido nos pareceres é significativo. No entanto, na maioria absoluta dos casos, eles não se apresentam como sugestão para uma medida judicial.

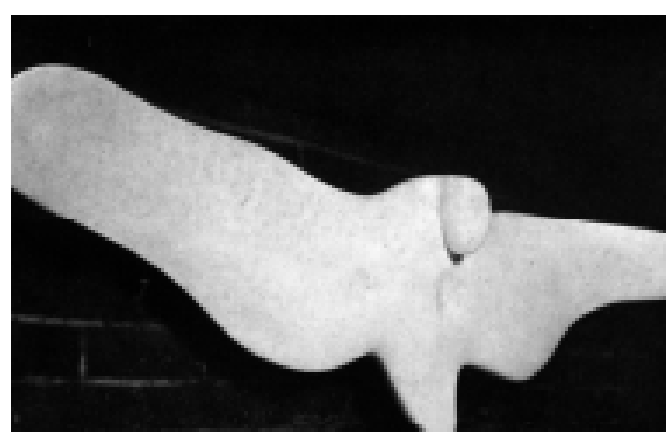

Quais seriam os principais itens que o parecer deveria responder? Por quê? $\mathrm{O}$ parecer tem valor de prognóstico? De um modo geral, essa pergunta não foi respondida sob a forma de itens. '[O parecer] deve fazer com que a parte seja conhecida, mostrar a relação com a família, trabalho etc. Deve citar falas, bibliografia. Há que se escrever para que algo aconteça, [o parecer] é uma possibilidade para que a parte seja ouvida'; [o parecer] é uma formulação que visa a história do sujeito, é uma aposta'; [o parecer] deve ouvir as partes, mostrar os motivos em jogo'. Há um conjunto de informações interessantes nessas respostas. Por um lado, a explicitação de que o parecer é um lugar atravessado por uma série de dispositivos estratégicos. É preciso, nesse sentido, que ele seja pragmático. Ainda aqui, a questão da visibilidade é nuançada. Ressalta-se que a parte tem algo a dizer sobre a sua presença na máquina judicial, mas que os dispositivos tradicionais (audiências, p.ex.) não seriam suficientes para representá-la naquele universo. Há como que um anacronismo, um descompasso entre o que se precisa ouvir e os recursos disponíveis. A atualização desses recursos, a sincronia entre o dispositivo e aquilo que se espera ouvir, que se precisa entender, seria, talvez, oferecida através dos pareceres da equipe técnica. Ainda é interessante 
acrescentar a referência feita à palavra aposta. Nela, parece ruir todo o ponto de certeza que os operadores jurídicos poderiam querer encontrar. Embora não seja comum, essa palavra também foi encontrada nos pareceres.

Quais os itens que não precisariam constar no parecer psicológico? Houve dificuldade em responder a essa questão. Contudo, houve algumas considerações de caráter mais geral: 'o relatório deve ser sintético'; 'há necessidade de marcar limites' etc. Um outro comentário apontou que não se trataria propriamente de definir itens que deveriam constar num parecer, pois o que fará a diferença e caracterizará o trabalho será um tipo peculiar de conclusão. Tal conclusão, por vezes, poderá até ter como base os mesmos tipos de itens que comporiam um parecer social, p.ex. De qualquer modo, quando comparadas às respostas dos operadores jurídicos, há um cuidado em não maximizar o alcance do estudo psicológico, isto é, há nitidamente o entendimento que a história do indivíduo cabe no relatório na medida em que auxilia na resolução de uma questão específica do processo. Em resumo, há uma expectativa de que não é a 'vida toda' do jurisdicionado que deve ser apresentada no parecer.

Sua formação e experiência profissional são exclusivas na Psicologia? Um dos psicólogos entrevistados foi estudante de Direito e concluiu uma especialização em Psicologia Jurídica. Outro é também agrônomo. Os demais formaram-se exclusivamente em Psicologia.

Há quanto tempo na VIJ? Apenas um dos psicólogos não está na $1^{\text {a }}$ VIJ desde 1999. Um dos demais tem experiência anterior de cerca de dois anos assessorando uma juíza no interior do Estado.

\section{O Parecer, Uma Ilusão?}

É interessante que um psicólogo tenha feito menção a uma 'conclusão a posteriori'. Essa menção alinhase e promove um sentido bem particular a uma outra afirmação vista acima, a de que se deve 'escrever para que algo aconteça'. Assinala-se, assim, de certo modo, que os efeitos esperados pela intervenção psicológica podem advir de um outro território que não o científico, embora, às vezes, como dito acima, seja preciso 'crer' que o espectro da ciência dite as normas da Psicologia Jurídica. Mas que intervenção os psicólogos podem realizar que não seja apenas aquela dedicada a uma suposta legitimação científica das medidas judiciais ${ }^{2}$ ?

Uma resposta possível, à qual pretendemos restringirnos no momento, já foi indicada por Rauter (1989). teve como objeto, especificamente, o universo penal.

A autora destaca como a aplicação de conceitos ditos científicos teria a função de realizar um julgamento antecipado do sujeito sobre o qual a intervenção do psicólogo teria ocorrido.

Conforme o recorte que efetuo, estaria implícito, nessas intervenções, um dispositivo que um outro autor denomina ilusão retroativa (Jankélévitch, 1989 e Bergson, 1993). Para o contexto no qual nos localizamos, a ilusão retroativa significa a apropriação de eventos no presente, com os quais interpreta-se o passado, de modo a concluir que não haveria outra forma ou resultado possível senão o que se apresenta. Nos termos de Rauter (1989, p. 20): "A reconstituição da história é uma montagem, cuja finalidade é confirmar no indivíduo o rótulo de criminoso".

Se conseguirmos nos desvencilhar da idéia de que o parecer é a decifração da personalidade do sujeito, tendo como base sua história, e que realizaria a priori seu julgamento conforme determinados parâmetros, deparamo-nos com as forças em jogo em sua elaboração.

Dessa forma, podemos dizer que a escritura de um parecer dá-se num espaço próprio - a máquina judiciária - durante um período em que os constrangimentos que operam sobre ela sugerem, a todo instante, a certeza de garantir, sob determinadas condições, o presente e o futuro com dados do passado, ou através de algum método dito científico. Todavia, e esta é a peculiaridade da era disciplinar, antes de ser preponderante saber 'o que aconteceu', trata-se de responder sobre a normalidade, bem como suas variantes: se tem 'estrutura psicológica adequada', quais 'as razões do desejo', quais os 'motivos de uma violência', quais as 'conseqüências da quebra de um vínculo', qual o 'perfil emocional para serem bons pais' etc. A partir das respostas obtidas, a medida aplicada guardará, quando necessário, correspondência com uma proposta 'educativa' ou 'terapêutica'.

No entanto, e fazendo valer alguns termos revelados nas entrevistas, como apresentar um parecer que conjugue os princípios do 'a posteriori' com o valor do prognóstico?

\section{Os Pareceres}

Quanto aos pareceres analisados, é preciso adiantar que, a despeito de suas especificidades, relativas, por exemplo, à orientação teórica do psicólogo, há linhas comuns que perpassam por todos. Tais linhas já se anunciaram nas respostas acima. Podese notar, ali, que há convergências significativas no modo como os grupos responderam às perguntas. 
Não se trata de afirmar que os pareceres teriam como preocupação exclusiva a produção de visibilidade/saber destinado ao juiz, mas o instrumento opera de modo a não poder prescindir desses referenciais. De modo esquemático e ideal, pode-se imaginar a composição parecer psicológico-parecer social como um 'retrato total' daquele que lhe é objeto, daí a afirmação de um operador do Direito: "nós intervimos no caso a partir dos relatórios, pois nós praticamente só encontramos as partes na hora da audiência. Vocês têm mais tempo, ficam em contato com elas...".

Assim, nos pareceres, é possível notar imediatamente que o destinatário é o juiz. Esse ponto é de extrema relevância, pois uma narrativa é construída a partir dos mais variados elementos: história pessoal, motivações, desejos e mesmo aparências. A noção de adequação está, de certo modo, presente nas análises feitas. Adequação, por exemplo, quando se fala de uma criança e seu desenvolvimento intelectual e emocional. Adequação e aparência entrecruzam-se, ainda, na descrição sobre o aspecto dos jurisdicionados, sejam crianças ou não: se estão limpos, saudáveis, arrumados, se são maduros ou não etc.

É interessante notar, também, porque os operadores jurídicos mencionam com tanta freqüência a palavra 'emocional' quase como sinônimo de psicológico. Ela comparece com destaque nos pareceres, embora, certamente, os relatórios não se resumam a esse aspecto. Na esteira dessa palavra, seguem-se, também com certo destaque, mas para descrever relacionamentos, duas outras: harmonioso e equivalentes. Entre a primeira e a segunda, é o sentido de equilíbrio, equilibrado, que se vai delineando. Assim, poderse-ia afirmar que se trata, no limite, de adaptação e suas variantes. Por vezes, há nos pareceres uma avaliação acerca da capacidade de se propiciar um ambiente favorável ao bom desenvolvimento infantil; em outras, aponta-se que determinados comportamentos devem ser evitados ou encorajados.

Ao colocarmos lado a lado pareceres e entrevistas, vê-se, mais claramente nestas, uma preocupação que, talvez devido a questões formais, não se apresenta nos primeiros: a linha tênue, e até certo ponto frágil, do reconhecimento que resta, ao fim de cada intervenção, algo sobre o que o parecer não pode falar. Talvez possamos dizer que os processos de habilitação para adoção são os que, à sua maneira, ilustram melhor esse limite. Ali, a história processual é praticamente nula, nenhum dado a orientar a intervenção, exceto a palavra daquele que afirma desejar ser um pai ou uma mãe. Num número limitado de entrevistas, onde o sentido avaliativo dificilmente é ultrapassado, o que podemos, de fato, saber ${ }^{4}$ ?

Retomando uma consideração anterior, poderíamos perguntar: não seria o lugar e a escritura do parecer um registro da história no processo que poderia apontar para as descontinuidades que marcam os sujeitos, de modo a fazer persistir, sempre, mesmo na letra do parecer, um imprevisível com o qual temos que lidar? Ou seja, não há em cada parecer um impossível de responder que deveria deixar marcas na intervenção realizada? Dessa forma, o parecer é parcial, incompleto, na medida em que seu sentido advirá também do jogo de forças e do lugar que os diversos destinatários impuserem à sua letra. É interessante notar, no entanto, que esses destinatários também passam, de modo igualmente parcial e ainda que de forma lenta, por mudanças promovidas pelo lugar assumido pelo psicólogo.

Não poderia o reconhecimento de um impossível, de um limite nessa letra que estamos chamando parecer, instaurar caminhos até então desconhecidos não só para nós, como também para os indivíduos trazidos à máquina judiciária e aos próprios operadores jurídicos?

Não se submeter à ilusão retroativa é explorar ao máximo o entendimento que um fragmento do presente não é, necessariamente, a expressão de um evento datado para ocorrer em um longínquo passado.

O parecer é um modo pelo qual o sujeito será representado num processo através da palavra daquele que o ouviu. Que ela reconheça sua força e seu limite em interpretar o passado, é algo necessário. Não restaria sempre ali algo que, ao final, nos incita, mas do qual menos se sabe quanto mais se avança? Reconhecer essa resistência é um imperativo que tem os seus riscos ${ }^{5}$.

Como escreveu Canguilhem (1973, p. 23), a Psicologia encontra-se numa encruzilhada na qual o caminho escolhido designará o lugar pelo qual responde, daí a pergunta: "dizei-me em que direção tendes, para que eu saiba o que sois?"

Mas, se o exame é um instrumento disciplinar e o parecer psicológico é um modo de sua atualização, o que mais podemos esperar?

\section{Uma Palavra, Ainda}

Embora se possa ouvir de alguns operadores do Direito que "a Psicologia não tem nada a ver com a Justiça" ou que não saibam o que o psicólogo pode ali fazer, é inquestionável que há muito foi criada uma série de condições que tornaram possível pensar sobre tal papel. Deve-se ressaltar que as intervenções próprias à Justiça e ao Direito

\section{"A reconstituição \\ da história é uma \\ montagem, cuja \\ finalidade é \\ confirmar no \\ indivíduo o rótulo de \\ criminoso".}

Rauter
4 Não é nosso objetivo avançar nos desdobramentos próprios a essa pergunta. Para uma abordagem pertinente e que auxiliará no entendimento das questões ligadas à adoção, ver Brunin, 1992 e Hamad, 2002.

5 A apresentação de Fernanda Otoni de Barros, 'Laudos Periciais: da Escrita à Escritura, um Percurso Ético', realizada no III Congresso IberoAmericano de Psicologia Jurídica, em São Paulo/1999, foi importante para a elaboração dessas questões. 
encontram-se modificadas a partir desse novo jogo de relações, que, sob o aspecto mais amplo, diz respeito às ciências humanas, e não à Psicologia em particular. Trata-se do que Foucault chamou de "justiça 'examinatória":

Não se quer dizer que da prisão saíram as ciências humanas. Mas se elas puderam se formar e provocar no êpistemê todos os efeitos de profunda alteração que conhecemos, é porque foram levadas por uma modalidade específica e nova de poder: uma certa política do corpo, uma certa maneira de tornar dócil e útil a acumulação dos homens. Esta exigia a implicação de correlações definidas de saber nas relações de poder: reclamava uma técnica para entrecruzar a sujeição e a objetivação: incluía novos procedimentos de individualização (Foucault,1989, p.266).

\section{"(...) lá onde há poder há resistência e, no entanto (ou melhor, por isso mesmo) esta nunca se encontra em posição de exterioridade em relação ao poder".}

Foucaul

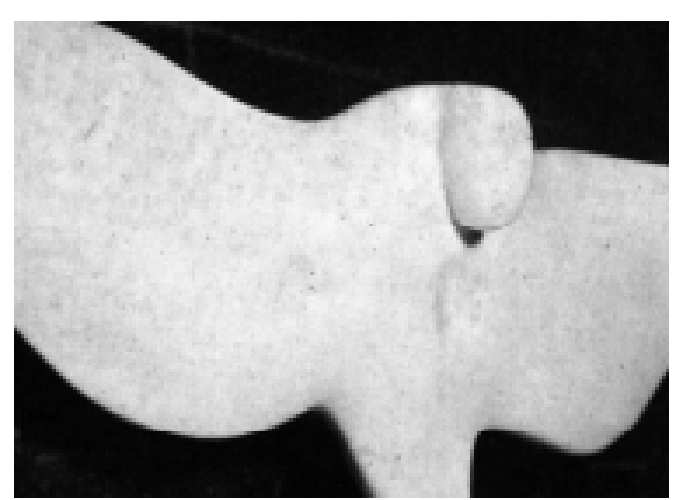

Essas considerações sinalizam que qualquer análise acerca da prática do psicólogo nos sistemas judiciais nunca poderá realizar-se exclusivamente no nível de uma técnica neutra, de um saber-fazer, onde as questões de eficácia ou eficiência poderiam ser separadas de uma dimensão ética e política. Como dito anteriormente, uma palavra falada, a análise escrita, um parecer, qualquer intervenção, portará não só os traços do lugar a partir de onde é produzida, como também terá, certamente, um alcance para além de seu objetivo imediato. Desse modo, é preciso que algumas afirmações, tais como as de que a Psicologia humaniza o Direito ou de que a Psicologia é um conhecimento científico sobre a subjetividade, útil às intervenções da Justiça, sejam por vezes interrogadas.

Dentro da mesma linha de argumentação precedente, segundo a exposição de Verani (1994), o "reforço da norma" e o "poder de determinar o certo e o errado" seriam as linhas que associariam a Psicologia ao Direito; seriam os signos de uma aliança que deveria ser repudiada. Ao mesmo tempo, em seu discurso, existia um apelo para que
Essa possibilidade de alianças para um objetivo diverso remete-nos a um enunciado de Foucault que tem sido bastante repetido, o qual sinaliza, certamente, para um melhor entendimento de sua analítica do poder (Machado, 1989, p. XIV): "onde há poder há resistência". Para citar de modo completo:

(...) lá onde há poder há resistência e, no entanto (ou melhor, por isso mesmo) esta nunca se encontra em posição de exterioridade em relação ao poder (Foucault, 1990, p. 91).

Trata-se, como Foucault e Machado esclarecem, de entender a noção de poder como estritamente relacional, tal qual um jogo de forças; por conseguinte, como não passível de pertencer a alguém, como se fosse quase sinônimo de mercadoria, de um bem. Da mesma forma, a resistência, ou, mais corretamente, os 'pontos de resistência' (Foucault, 1990, p. 91), não nos devem deixar pensar que haveria...

...um lugar da grande Recusa (...) Mas sim resistências, no plural, que são casos únicos: possíveis, necessárias, improváveis, espontâneas, selvagens, solitárias, planejadas, arrastadas, violentas, irreconciliáveis, prontas ao compromisso, interessadas ou fadadas ao sacrifício (...) [as resistências] não podem existir a não ser no campo estratégico das relações de poder (Foucault, 1990, p. 91).

Esses enunciados são retomados posteriormente por Foucault (1994b) a fim de explicitar-lhes o vigor e a pertinência no conjunto de suas elaborações.

Ora, dada a materialidade que o parecer psicológico assume no contexto judicial, não poderíamos ver nele, também, uma das formas de manifestação do que chamamos 'pontos de resistência'? Daí, por exemplo, a referência feita ao longo deste artigo a uma certa descontinuidade entre a função do psicólogo e os constrangimentos a que está sujeito e que se traduzem nas decisões que realiza. Descontinuidade que, para usar uma palavra arriscada, poderíamos chamar liberdade. Não por acaso invocamos essa palavra aqui, haja vista que sobre ela Foucault lança particular atenção em 'Le Sujet e le Pouvoir':

O poder não se exerce senão sobre 'sujeitos livres', e enquanto são 'livres' - entendamos aí sujeitos individuais ou coletivos que têm diante deles um campo de possibilidade onde várias condutas, várias reações e diversos modos de comportamento podem ter lugar. Aí onde as determinações são saturadas, não existe relação de poder: a escravidão não é uma relação de poder quando o homem está preso aos ferros (trata-se então de uma relação física de constrangimento), mas justamente quando 
pode se deslocar e no limite escapar (Foucault, 1994b, pp. 239-240).

Assim, conforme nossa argumentação, as considerações que Marie Lacroix, juíza de assuntos familiares, na França, fez no I Encontro Psicossocial Jurídico do Tribunal de Justiça do Distrito Federal e Territórios foram de inestimável valor.

A primeira consideração que gostaríamos de reproduzir aqui é o entendimento que a intervenção da equipe interdisciplinar na cena jurídica não se limitaria à formação de prova; a segunda salienta que a ação, qualquer que seja ela, precisa ser marcada por uma incompletude, um limite, para que possa se realizar. Ela ilustra essa consideração com uma citação: "quando se sabe tudo, não se pode julgar" ${ }^{6}$.

Para contextualizar corretamente as afirmações acima, é preciso acrescentar que a primeira se refere a um complexo aparelho de apoio ao magistrado, do qual foi sublinhada a função do conciliador (sendo mencionada, também, toda uma coorte de outras funções: assistentes sociais, serviços de saúde, órgãos governamentais etc.). Tal aparelho teria por função intervir no sujeito de modo que a sentença judicial fosse realmente efetiva, isto é, resultasse em benefício para ele ou para a sociedade. Assim, por exemplo, em alguns casos, o magistrado pode suspender o processo por até seis meses para que o casal litigante freqüente alguns encontros de mediação. $\bigcirc$ segundo poderia ser entendido como uma indicação de que o saber do juiz, hoje, demanda uma interação contínua com outros saberes (das ciências humanas, em particular) de modo a poder realizar-se de modo efetivo. Ambas as afirmações ilustram, ao seu modo, o painel que esboçamos acerca da relação Psicologia-Direito no que diz respeito ao exame, à disciplina e à norma.

No entanto, devemos ainda deter-nos um pouco mais na citação de Lacroix. Há que se destacar que a juíza não tinha em perspectiva exclusivamente os magistrados. Poder-se-ia dizer que o quotidiano atualiza, das mais diversas maneiras, para os psicólogos e para os operadores jurídicos, limites que se traduzem em impasses. $\mathrm{O}$ modo de responder a eles eventualmente guarda diferenças conforme se trate de um psicólogo, de um assistente social, juiz etc. Então, são apresentadas, a princípio, duas interpretações para aquela frase: uma, que creditaria à possibilidade, em maior ou menor grau, de sutura de um saber pelo outro; outra, que radicaliza a idéia de um não-saber, impossibilidade de recobrimento de um saber pelo outro, mas que, no entanto, não inviabiliza uma tomada de decisão; pelo contrário, é sua condição de possibilidade.
Já afirmamos que ao menos uma de nossas atribuições, associada ao parecer, seria a de construir uma narrativa, uma história, através da qual os sujeitos se inscreveriam no universo judicial, narrativa pela qual um sujeito passa a ser reconhecido de determinada maneira. Todavia, pode-se pensar o parecer como um campo onde uma correlação de forças se estabelece - tal como dito anteriormentee o modo como o psicólogo estará posicionado aí (conforme nossas referências à descontinuidade, à impossibilidade e à liberdade, p.ex.) poderá tornar o instrumento uma ferramenta de resistência, tal como especificado por Foucault.

Se essa hipótese faz algum sentido, é preciso entender que a equipe técnica, na máquina judiciária, constrói lugares, cria sistemas de interpretação que dão significados a nomes como requerentes, requeridos, adolescente infrator, adotando, violência. Mais importante, ao elaborar essa narrativa, estamos criando uma história, isto é, um passado e um futuro onde esses nomes adquirem uma materialidade própria. A esta altura, não é difícil notar que, para participar da constituição dessas histórias, seria preciso que as certezas fossem poucas e que se pudesse dizer "não sei". É porque não se sabe que se pode buscar um sentido nos enunciados que partem do outro. Assim, ao falarmos da valorização de um tipo de "não saber", estamos fazendo apelo a um uso positivo do tempo, isto é, estamos afirmando que pode haver uma dissimetria entre o passado e o futuro e que o sujeito deve responder por suas escolhas.

Ao invocarmos um uso positivo do tempo, nada mais fazemos do que retomar a consideração feita anteriormente sobre o 'a posteriori' e a 'ilusão retroativa'. Deve ser lembrado que, ali, quando falamos dos pareceres e entrevistas, surpreendeunos o uso e o apelo à palavra aposta. Naquele momento, já se insinuava que algo escapa, necessariamente, ao parecer e, de certa maneira, é isso que, em maior ou menor medida, pode tornálo uma peça importante nas estratégias de resistência (cf. Foucault, 1991; Castel, 1991 e Fontana, 1991).

Por fim, cabe retornar à resposta de um dos psicólogos entrevistados e fazer dela um voto que será também o nosso. Voto que denuncia as ambigüidades, as contradições e as correlações de força que fazem do parecer um campo de múltiplas batalhas, cenário onde figuras e personagens, às vezes, se fazem de difícil distinção. É esse entrelaçamento que faz do poder e da resistência duas noções indissociáveis na história que descrevemos: "[Espero] que o parecer sirva cada vez menos como uma resposta exclusiva ao juiz..."
6 André Malroux foi indicado como o autor da fiase, porém, sem referencias. 


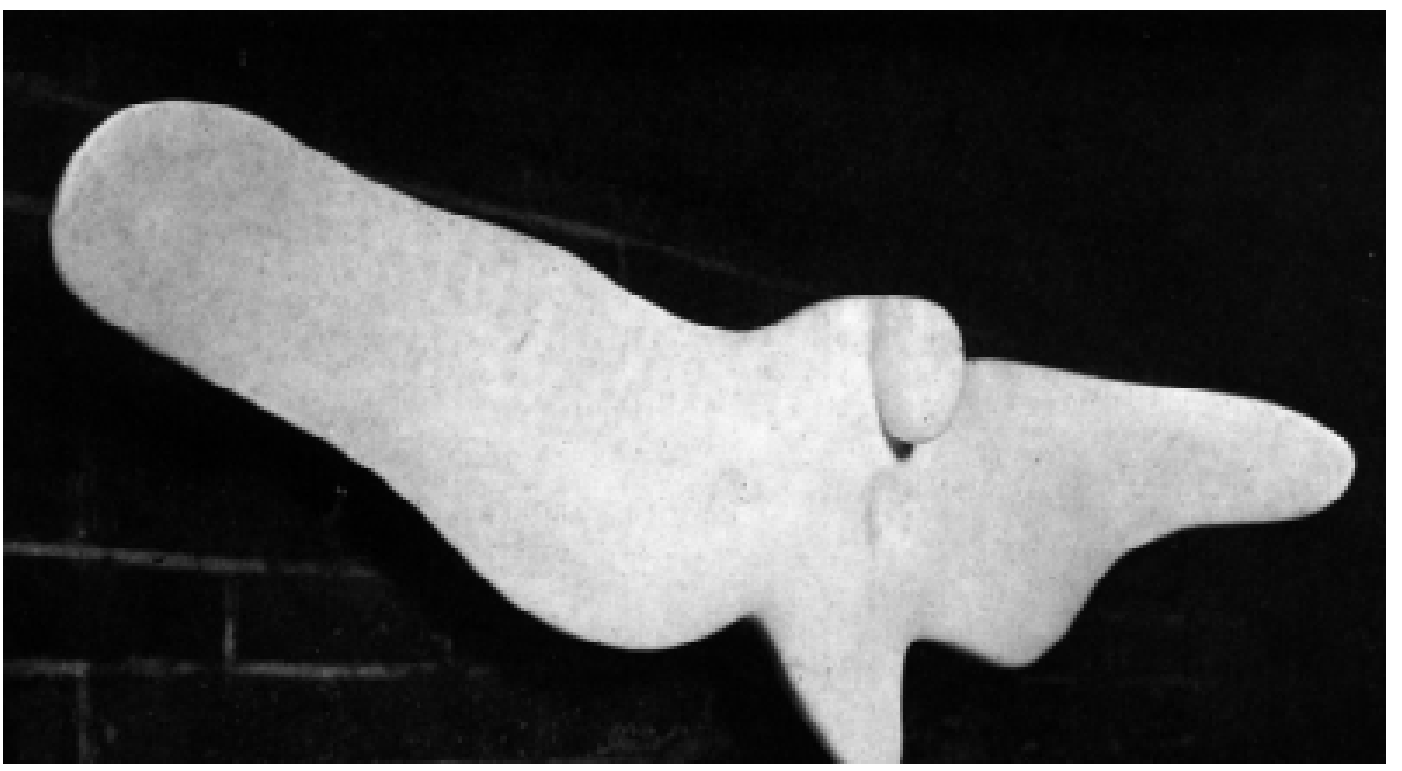


José César Coimbra

Praia do Flamengo, 314/5,

Flamengo, Rio de Janeiro, RI, 22210-030,

Tel.:21 2237-0323

E-mail:arcoim@yahoo.com.br

Recebido 27/03/02 Aprovado 08/08/04

BERGSON, H. La Pensée et le Mouvant. Paris: Quadrige/PUF,1993.

BRUNIN, J. P. Adoption et Sélection. L'Enfant et la Famille, 5, septembre,1992, pp. 63-68.

CANGUILHEM, G. O que é a Psicologia? Revista Tempo Brasileiro, 30/ 31, pp.104-123

CASTEL, R. Os Médicose os Juízes. In Foucault, Michel (org.). Eu, Pierre Rivièrre, que degolei minha mãe, minha irmã e meu irmão... Rio de Janeiro: Graal, 1991, pp.259-276.

EWALD, François Foucault, a Norma e o Direito. Lisboa: Vega,1993.

FONTANA, A. As Intermitências da Razão. In Foucault (org.) Eu, Pierre Rivièrre, que Degolei Minha Mãe, Minha Irmã e meu Irmão... Rio de Janeiro: Graal, 1991, pp.277-294.

FOUCAULT, M. (org.) Eu, Pierre Rivièrre, que Degolei Minha Mãe, Minha Irmã e meu Irmão.. Rio de Janeiro: Graal,1991, pp.IX-XV.

FOUCAULT, M. Vigiar e Punir. Petrópolis: Vozes,1988.

FOUCAULT,M. Verdade e Poder. In A Microfísica do Poder. Rio de Janeiro: Graal,1989, pp. 1-14. História da Sexualidade I: a Vontade de Saber. Rio de Janeiro: Graal,1990.
(1994). La Verité et les Formes Juridiques. In Dits et Écrits II. Paris: Editions Gallimard,1994.

(1994a). Les Mailles du Pouvoir. In Dits et Écrits IV. Paris: Editions Gallimard,1994.

(1994b). Le Sujet et le Pouvoir. In Dits et Écrits, IV. Paris: Éditions Gallimard,1994b.

HAMAD, N. A Criança Adotiva e Suas Famílias. Rio de Janeiro: Companhia de Freud, 2002.

JANKÉLÉVITCH, V. Henri Bergson. Paris: Quadrige/PUF,1989.

MACHADO, R. (org.) Introdução. Por uma Genealogia do Poder. In A Microfísica do Poder. Rio de Janeiro: Graal,1989, pp.VII-XXIII.

RAUTER, C. Diagnóstico Psicológico do Criminoso: Tecnologia do Preconceito. Revista do Departamento de Psicologia da UFF,1989, pp. 9-22.

RIZZINI, I. A Criança no Brasil Hoje-Desafio para o Terceiro Milênio. Rio de Janeiro: Ed. Universidade Santa Úrsula,1993.

VERANI, S. Alianças Para Liberdade. In Brito, LeilaM. T. (org.) Psicologia e Instituições de Direito: a Prática em Questão . Rio de Janeiro: Comunicarte/UERJ/CRP 05,1994, pp.14-20. 